\title{
Development of a genetic evaluation for body condition score for Canadian Holsteins
}

\author{
S. Loker, ${ }^{* 1}$ C. Bastin, $\nmid$ F. Miglior, $¥ \S^{2}$ A. Sewalem, $¥ \S$ L. R. Schaeffer, ${ }^{*}$ J. Jamrozik, ${ }^{*}$ V. Osborne,\# and A. Ali" \\ ${ }^{*}$ Centre for Genetic Improvement of Livestock, Department of Animal \& Poultry Science, University of Guelph, Guelph, ON, Canada, N1G 2W1 \\ †University of Liège, Gembloux Agro-Bio Tech, Gembloux, Belgium, B-5030 \\ ‡uelph Food Research Centre, Agriculture and Agri-Food Canada, Guelph, ON, Canada, N1G 5C9 \\ §Canadian Dairy Network, Guelph, ON, Canada, N1K 1E5 \\ \#Centre for Nutrition Modelling, University of Guelph, Guelph, ON, Canada, N1G 2W1 \\ IIDepartment of Mathematics and Statistics, University of Guelph, Guelph, ON, Canada, N1G 2W1
}

\begin{abstract}
Valacta (Sainte-Anne-de-Bellevue, Québec, Canada) is the Canadian Dairy Herd Improvement organization responsible for milk recording in Québec and Atlantic provinces. Up to 14 first-lactation body condition score (BCS) records were collected per cow (average of 2.5 records per cow), allowing the trait to be described by a random regression animal model so that animals could be ranked by the shape of their BCS curve. However, Valacta's BCS are available from Québec herds only and the long-term objective of this research is to develop a nationwide genetic evaluation of sires and cows for BCS. Alternatively, Holstein Canada (Brantford, Ontario, Canada) collects type trait records nationwide, primarily for first-lactation cows. Holstein Canada typically collects a single record per trait, so that selection for Holstein Canada BCS would be based on overall BCS level rather than the shape of the BCS curve. Several different methods of genetically evaluating Valacta's BCS were investigated, including consideration of average BCS level across lactation, the amount of fluctuation in the BCS curve during lactation, and combinations of BCS level and BCS fluctuation. Sires with $\geq 25$ daughters were compared (as opposed to comparing cows) because their BCS estimated breeding values (EBV) are based on more information, and so should be more reliable. Of the different methods of calculating Valacta BCS EBV, ranking bulls based on overall BCS level gave the best results in that their daughter phenotypic BCS curves showed limited loss in early lactation BCS and replenished condition by the end of lactation. Whereas Valacta's BCS were analyzed using a random regression animal model, Holstein Canada only needs to collect 1 BCS record per cow at
\end{abstract}

\footnotetext{
Received September 11, 2012.

Accepted February 18, 2013.

${ }^{1}$ Current address: Livestock Improvement Co., 605 Ruakura Rd. Newstead, Hamilton, New Zealand.

${ }^{2}$ Corresponding author: miglior@cdn.ca
}

classification and the resulting BCS EBV was strongly correlated with Valacta's BCS EBV. Furthermore, because Holstein Canada's BCS are collected nationally and Valacta's BCS are not, a national genetic evaluation for Holstein Canada's BCS is more convenient. The results of this study do not eliminate the possibility of a genetic evaluation of BCS as a longitudinal trait, but indicate that other methods of calculating Valacta BCS EBV should be explored. Until that time, genetically evaluating Holstein Canada's BCS is simple, easily implemented, and may be effective in altering the level and shape of the genetic BCS curve.

Key words: body condition score, genetic evaluation, type trait, random regression model

\section{INTRODUCTION}

Selection for functional traits has been gaining more attention in the last decade (Kadarmideen, 2004; Miglior et al., 2005; Weigel, 2006). Few countries perform genetic evaluations for health traits using direct disease information, and many countries perform genetic evaluations on fertility traits (Interbull, 2011). However, health and fertility traits tend to be lowly heritable (Wall et al., 2003; Jamrozik et al., 2005; Neuenschwander, 2010; Koeck et al., 2012a). Lowly heritable traits require data collection on many daughters for reliable estimates of bull breeding values (Shook, 1989; Hoekstra et al., 1994), making it expensive to prove a bull. Health and fertility traits are often difficult to measure (Dal Zotto et al., 2007; Bastin et al., 2010a), and can be susceptible to data quality issues due to improper recording (Kadarmideen and Coffey, 2001; Neuenschwander, 2010), or variations in trait definitions among producers (Neuenschwander, 2010). Indicator traits may be of benefit if they are more heritable, easier to record, and are strongly genetically correlated with health and fertility traits (Berry et al., 2003a). Body condition score is a subjective measure of the amount of metabolizable energy stored on a live animal 
(Edmonson et al., 1989), and could be an indicator trait for health and fertility. Body condition score has been shown by several studies to have a moderate heritability, ranging between 0.20 and 0.51 (Jones et al., 1999; Koenen et al., 2001; Berry et al., 2002, 2003b; Loker et al., 2011, 2012a,b). Edmonson et al. (1989) outlined how BCS can be quickly and easily recorded using visual cues on freely moving dairy cattle with very little interassessor variability, and no significant cow assessor interaction. Several studies reported moderate-to-strong genetic correlations between BCS and various health (Dechow et al., 2004; Neuenschwander, 2010; Koeck et al., 2012b) and reproduction traits (Pryce et al., 2001; Banos and Coffey, 2010; Bastin et al., 2010a,b).

The current study used Canadian BCS data. Previous Canadian BCS research has used data provided by Valacta, a Canadian milk recording agency based out of Sainte-Anne-de-Bellevue (Québec, Canada). Valacta collects several BCS records per cow in each lactation, permitting analysis of the trait with a random regression animal model. The prospect of a future genetic evaluation of BCS using a random regression animal model is appealing because it permits ranking and selection of animals based on the unique shape of their BCS curve, especially if selection could permit limited early lactation BCS loss and sufficient late lactation tissue reserve replenishment. Using Valacta BCS data, Neuenschwander (2010) and Bastin et al. (2010a) found a general positive genetic correlation between BCS and both health and reproductive performance. Valacta's BCS were found to be moderately heritable (0.22 in first lactation), and average daily BCS was strongly genetically correlated across the first 3 lactations (Loker et al., 2011). Although not unity, the genetic correlations of Valacta's BCS between parities were still strong (above 0.80, with low posterior standard deviations), indicating that most of the variation observed in BCS was controlled by the same genes for each of the first 3 lactations. Thus, first-lactation BCS records would be sufficient for genetic evaluation purposes such that EBV would be available early in life. Before using BCS to indirectly improve health and fertility, it is important to verify its relationship with other economically important traits. Therefore, research was performed by Loker et al. (2012a) to estimate relationships between Valacta's BCS and milk production traits in first-lactation Canadian Holsteins. That study proposed that simultaneous selection for both BCS and milk production traits should be considered, mainly due to the unfavorable genetic correlation between BCS and milk yield (i.e., higher producers tended to have lower BCS). The level of association of BCS with milk production traits was not constant over the lactation. Early lactation BCS had the most favorable genetic correlation with milk production traits in that it had the weakest negative genetic correlation with milk yield. Thus, early lactation BCS EBV shows potential for selection. In other words, although generally a negative genetic correlation exists between milk production and BCS, simultaneous selection on milk production and early lactation BCS EBV may result in the greatest genetic gain per unit time for those traits rather than using BCS EBV from another stage of lactation.

The recent Canadian BCS research summarized above investigated Valacta's BCS, collected from Québec herds. Traits recorded nationwide that are genetically correlated with Valacta's BCS are required for a national genetic evaluation of longitudinal BCS. Holstein Canada (Brantford, Ontario, Canada) performs type classifications for dairy herds nationwide. Holstein Canada's BCS and other type traits could be useful in conjunction with Valacta's BCS for a national genetic evaluation of the longitudinal Valacta BCS trait, which would allow all Canadian Holsteins to be ranked based on their unique BCS lactation curve. An alternative would be to select for level of BCS, in which case Holstein Canada's BCS could be sufficient for selection. Because Holstein Canada's BCS is recorded routinely across Canada (whereas Valacta's BCS is not), it is more convenient to use for a national genetic evaluation. Also, the method of analysis of Holstein Canada's BCS would be less computationally intensive than using a random regression animal model to genetically evaluate Valacta's BCS. Thus, if the EBV of Holstein Canada's BCS is the same or similar to Valacta's BCS EBV, then using Holstein Canada's BCS may be more efficient. The objective of this study was to compare different methods of genetically evaluating BCS.

\section{MATERIALS AND METHODS}

Body condition scores from 2001 to 2010 were available, collected from Québec herds by Valacta. Up to 14 BCS records were collected per cow (average of 2.5). Similar to Loker et al. (2012b), who also used Valacta's BCS, the distribution of Valacta's BCS records was fairly even over the lactation. Body condition score, angularity (ANG), and chest width (CW) records from Holstein Canada were available from 2005 to 2010. Angularity and CW were chosen to analyze with BCS because they are body traits related to cow size, and previous work on these Holstein Canada traits found ANG and CW to be strongly genetically correlated with Holstein Canada's BCS ( -0.70 and 0.72, respectively, with posterior standard deviations of 0.04 for both correlations; Loker et al., 2010). Other studies have found that the genetic correlation of ANG and $\mathrm{CW}$ with BCS is strong, ranging between -0.84 and 
-0.77 for ANG, and 0.73 and 0.77 for CW (Veerkamp and Brotherstone, 1997; Berry et al., 2004). Hence, ANG and $\mathrm{CW}$ should provide additional data related to Holstein Canada's BCS that will increase the reliability of BCS EBV.

Valacta and Holstein Canada both use the chart in Edmonson et al. (1989) as a basis for training assessors. Cows are assessed using this chart based on visual appraisal, and are scored on a scale from 1 (thin) to 5 (fat), using increments of 0.25. Angularity was taken on a scale from 1 (nonangular, close ribs) to 9 (very angular, open ribbed). Chest width was taken on a scale from 1 (narrow) to 9 (wide). Both ANG and CW were recorded using single-unit increments.

Access to pedigree records was provided by Canadian Dairy Network (Guelph, ON, Canada). All known ancestors up to 14 generations back were included in this study. Only first-lactation data were used for the analyses. Animals that appeared in more than one herd, or that possessed more than one first-lactation calving date were removed (as this data was considered faulty). For both Valacta and Holstein Canada's BCS traits, herds had to have a BCS standard deviation of $\geq 0.25$ for the BCS recording to be considered reliable for those herds. Records were restricted to those taken between 5 and 305 DIM. Age at calving was restricted to 19 to $40 \mathrm{mo}$.

\section{Edits Specific to Valacta Data}

Valacta BCS records in classes of herd $\times$ scoring date with $<5$ records were deleted. In accordance with the distribution of the Valacta data, 4 age-at-calving classes were formed ( $\leq 24,25-26,27-28$, and $\geq 29 \mathrm{mo}$ ) and 5 year-of-calving classes were formed (1997-2003, 20042005, 2006-2007, 2008, and 2009-2010). Four seasons of calving (January-March, April-June, July-September, and October-December) were defined. These were used to form age $\times$ year $\times$ season $(\mathbf{A Y S})$ of calving classes, and herd $\times$ calving year classes $(\mathbf{H Y})$. No AYS classes had $<5$ records (the range was 20 to 4,295 records per class), and the HY variable was a random effect in the model used for analysis of Valacta's BCS.

\section{Edits Specific to Holstein Canada Data}

Reclassification records were removed, so a single record was available per animal. A classification round in Canada is a periodic rotation of approximately 8 mo by which all herds are visited by a breed classifier. Each classifier's first round of BCS was removed because BCS was assumed to be recorded less accurately, as they were still in training to classify this new trait. In accordance with the distribution of the data, 9 age- at-calving classes were formed $(\leq 23,24,25,26,27,28$, 29-30, 31-32, and $\geq 33 \mathrm{mo}$ ), and 10 stages of lactation classes were created, with a class for each month of lactation, and months $>10$ grouped together; these were used to form age at calving $\times$ stage of lactation $(\mathbf{A S T})$ classes. Herd $\times$ classification round, and herd $\times$ round $\times$ classifier $($ HRC) classes were formed. Herd $\times$ round classes with $\geq 5$ records were kept. Additionally, there were 9 classification rounds in the Holstein Canada data set between 2005 and 2010. To ensure that type traits were collected over a reasonable span of time, each herd was required to have records in $\geq 6$ of the 9 possible classification rounds. No AST classes had $<5$ records (the range was 353 to 17,330 records per class), and the HRC variable was a random effect in the model used for analysis of Holstein Canada's traits.

\section{Variance Component Estimation for Valacta and Holstein Canada Traits}

Holstein Canada type trait data were merged with Valacta's BCS data set by animal. Before merging Holstein Canada and Valacta data, herds that did not possess records in both data sets were removed. Specifically, herds had to have a minimum of 50 animals, with $60 \%$ of the animals having records in both data sets. This left 99 acceptable herds. There were 6,981 cows with Valacta BCS records (average of 2.5 records per cow), 6,965 cows with a Holstein Canada BCS record, and 7,927 cows with a record for ANG and CW (Holstein Canada's BCS was not always recorded when ANG and CW were). There were 5,869 animals with records in both Valacta and Holstein Canada data sets; 1,202 sires had daughters with Valacta BCS records and 1,229 sires had daughters with Holstein Canada records; 1,035 sires had daughters in both data sets.

Because a genetic evaluation for Holstein Canada's BCS may be more efficient than a genetic evaluation for Valacta's longitudinal BCS, a multivariate model was used to analyze Holstein Canada's BCS with ANG and CW. The purpose of analyzing Holstein Canada's BCS without Valacta's BCS was to estimate the correlation between Holstein Canada's BCS EBV and Valacta's BCS EBV. If the $2 \mathrm{EBV}$ are strongly correlated, using Holstein Canada's BCS for a genetic evaluation may be a preferred alternative because of the simplicity of its calculation, and because it is recorded routinely across Canada. For the multivariate analysis of Holstein Canada's BCS with ANG and CW, 100 herds with $\geq 50$ animals were randomly selected. This left 8,906 cows classified for BCS, ANG, and CW, and 1,380 cows that were only classified for ANG and CW. The models [Valacta + Holstein Canada (VAL+HC) and Holstein Canada's BCS EBV, calculated from a 
multivariate model $\left.\left(\mathbf{H C}_{\text {all }}\right)\right]$ used to analyze the data are described below.

$\boldsymbol{V A L}+\boldsymbol{H C}$ Model. A multivariate model was used to analyze Valacta's BCS and Holstein Canada's BCS, ANG, and CW. Valacta's BCS was described by the following equation:

$$
\mathbf{y}=\mathbf{X} \boldsymbol{\beta}+\mathbf{Z}_{1} \mathbf{h y}+\mathbf{Z}_{2} \mathbf{a}+\mathbf{Z}_{3} \mathbf{p}+\mathbf{e},
$$

where $\boldsymbol{\beta}$ was the vector of fixed herd $\times$ scoring date effects, and of fixed regression coefficients for AYS effects; hy was the vector of random regression coefficients for $\mathrm{HY}$ effects; a was the vector of random regression coefficients for additive genetic effects; $\mathbf{p}$ was the vector of random regression coefficients for permanent environmental ( $\mathbf{P E}$ ) effects; $\mathbf{X}, \mathbf{Z}_{1}, \mathbf{Z}_{2}$, and $\mathbf{Z}_{3}$ were incidence matrices assigning observations to effects; and $\mathbf{e}$ was a vector of random residuals.

Holstein Canada's BCS, ANG, and CW were described by the following equation:

$$
\mathbf{y}=\mathbf{X} \boldsymbol{\beta}+\mathbf{Z}_{4} \mathbf{h r c}+\mathbf{Z}_{2} \mathbf{a}+\mathbf{Z}_{3} \mathbf{p}+\mathbf{e},
$$

where $\boldsymbol{\beta}$ was the vector of fixed AST and herd $x$ classification round effects; hrc was the vector for the random HRC effects; a was the vector of random additive genetic effects; $\mathbf{p}$ was the vector of random environmental effects, accounting for common, nongenetic, animal-specific environmental effects in common between Valacta's BCS and Holstein Canada's traits; $\mathbf{X}, \mathbf{Z}_{2}, \mathbf{Z}_{3}$, and $\mathbf{Z}_{4}$ were incidence matrices assigning observations to effects; and $\mathbf{e}$ was a vector of random residuals.

Legendre polynomials of order 2 were used to describe regression curves for Valacta's BCS. Only a limited number of Valacta BCS records were available per animal (2.5, on average), and a similar study by Berry et al. (2003b) showed little advantage to using Legendre polynomials of order 3 instead of order 2 . As in Berry et al. (2003b), Negussie et al. (2008), and Bastin et al. (2010a), within-animal environmental covariance among traits was modeled by the PE effect. This effect allowed for a cow-specific, nongenetic link between the traits of the 2 data sets. Without the PE effect, the genetic component of the model became inflated for Valacta's BCS, resulting in a heritability estimate (above 0.60) that did not follow previous research on this trait, and did not match heritability obtained when Valacta's BCS was analyzed alone. Additionally, residual covariances between Valacta's BCS and the other traits were set to zero because the traits of the 2 data sets were recorded from 2 separate systems, and any residuals were assumed to be independent. If some residual covariance existed between Valacta's BCS and the other traits, this may have been absorbed by other random components of the model (Berry et al., 2003b), such as the PE component. Authors of the current study found this necessary to facilitate the estimation of PE correlation between Valacta BCS and Holstein Canada traits and to avoid inflation of Valacta's additive genetic variance.

Expectations and covariance structure for the random effects were as follows:

$$
\begin{gathered}
\mathbf{E}(\mathbf{y})=\mathbf{X b}, \mathbf{E}(\mathbf{h y})=0, \mathbf{E}(\mathbf{h r c})=0, \mathbf{E}(\mathbf{a})= \\
0, \mathbf{E}(\mathbf{p})=0, \mathbf{E}(\mathbf{e})=0
\end{gathered}
$$

and

$$
\begin{gathered}
\mathrm{V}(\mathbf{h y})=\mathbf{I} \otimes \mathbf{Q}_{0}, \mathrm{~V}(\mathbf{h r c})=\mathbf{I} \otimes \mathbf{T}_{0}, \mathrm{~V}(\mathbf{p})= \\
\mathbf{I} \otimes \mathbf{P}_{0}, \mathrm{~V}(\mathbf{a})=\mathbf{A} \otimes \mathbf{G}_{0}, \mathrm{~V}(\mathbf{e})=\mathbf{E}
\end{gathered}
$$

where $\mathbf{b}$ is a vector of fixed effects, $\mathrm{V}$ is the variance, $\otimes$ is the Kronecker product (Searle, 1982), I represents an identity matrix, $\mathbf{A}$ is the additive relationship matrix, $\mathbf{Q}_{0}$ is a (co)variance matrix for $\mathrm{HY}$ regression coefficients, $\mathbf{T}_{0}$ is a (co)variance matrix for HRC random effects, and $\mathbf{P}_{0}$ and $\mathbf{G}_{0}$ are (co)variance matrices for $\mathrm{PE}$ and additive genetic regression coefficients, respectively. Matrix $\mathbf{E}$ is a block-diagonal residual (co)variance matrix. Residual covariances were assumed to be heterogeneous across 3 intervals of DIM ( 5 to 45,46 to 115 , and 116 to 305 DIM). Within a given DIM interval, residual covariances between Valacta's BCS and other traits were set to zero, whereas those among Holstein Canada's traits were allowed to differ from zero. All residual covariances among traits between different DIM intervals were assumed to be zero. All random effects were assumed to be normally distributed.

$\boldsymbol{H} \boldsymbol{C}_{\text {all }}$ Model. A multivariate model was used to analyze Holstein Canada's BCS, ANG, and CW. The statistical model and expectations and covariance structure were the same as those in the VAL $+\mathrm{HC}$ model that apply to Holstein Canada's BCS, ANG, and $\mathrm{CW}$, except a PE effect was not included, and because this data was not as well distributed over the lactation as Valacta's data, residual variance was considered constant over the lactation. Additionally, the official genetic evaluation system of type traits in Canada does not have multiple residual variances, and we wanted to simulate the official evaluation as much as possible.

Variance components were estimated using DMU software (Madsen and Jensen, 2008) by a Bayesian approach via Gibbs sampling. Prior values were set arbitrarily to 0.03 for variances and 0 for covariances. Posterior means of (co)variance components were esti- 
mated using 80,000 samples after a burn-in of 20,000 samples. The convergence of Gibbs samples was monitored by visual inspection of the plot of realizations for selected covariance components.

Heritability was defined as the ratio of additive genetic variance to phenotypic variance (the sum of variances of random effects and residual variance). For the longitudinal analysis combining Valacta's BCS with Holstein Canada's BCS, ANG, and CW, daily heritability was defined as the ratio of additive genetic variance to phenotypic variance on a given DIM. Average daily heritability and genetic and PE correlations were obtained by summing daily heritabilities, or genetic or PE correlations from 5 to 305 DIM and dividing by 301. All heritabilities, genetic correlations, and PE correlations will be presented with posterior standard deviations in parentheses.

\section{$E B V$}

Variance components estimated from the Gibbs procedure described above were applied to the VAL $+\mathrm{HC}$ and $\mathrm{HC}_{\text {all }}$ models. The DMU software was used to obtain BLUP solutions.

$\boldsymbol{V A} \boldsymbol{L}+\boldsymbol{H C}$ Model. Three breeding values for Valacta's BCS were estimated per animal, one for each Legendre polynomial covariate (including the intercept). Five methods for calculating an overall Valacta BCS EBV were compared.

(1) Area Under the Curve $\mathrm{EBV}$. For each animal, the 3 Valacta BCS EBV were used to calculate a genetic BCS curve, and the area below the curve but no lower than the lowest point of the BCS curve was calculated. Figure 1 displays 2 theoretical genetic BCS curves and illustrates that the area under the curve (AUC) is high for one of the curves and is low for the other, despite the fact that the average BCS for each curve is approximately 3.40. Greater values would be calculated for animals that experience large fluctuations in their genetic BCS curve, which would be considered unfavorable. Lower values (which in this case are more favorable) would be calculated for animals with a steady BCS, which genetically produce milk without needing to mobilize much BCS because they are more efficient converters of feed to milk. Theoretically, animals with no change in BCS from beginning to end of lactation would be favored, as their "curve" would be a straight line with no slope. This assumes that selection for AUC puts equal weighting on reducing fluctuation of the BCS curve at different lactation stages.

(2) Intercept $\boldsymbol{E B} \boldsymbol{V}$. Alternatively, the height of each animal's BCS curve [i.e., the intercept EBV (INT)] is another option for ranking and selecting animals. Other studies have found that, genetically, a greater BCS level is associated with improved health and fertility (Pryce et al., 2000; Dechow et al., 2004; Bastin et al., 2010a,b; Koeck et al., 2012b). Roche et al. (2007) determined that the optimal calving BCS for increased milk production was 3.5 (on a 5-point scale), although that study was on a pasture-based system, so the recommended calving BCS may be slightly higher than what should be recommended for the average Canadian Holstein herd. The average Canadian Holstein BCS at calving is about 2.9 (on a 5-point scale) for parity-1 cows, and it is generally accepted that this BCS level is too low. A calving BCS above or below the optimal level is related to a greater risk of health and fertility problems, and to an associated decline in production. Thus, selection for greater overall BCS might be beneficial to the population.

(3) $\boldsymbol{A} \boldsymbol{U} \boldsymbol{C}-\boldsymbol{I N T}$. The AUC and INT values were standardized. Both standardized terms had an average of 0 with a standard deviation of 1 . The intercept term was subtracted from the AUC value. A lower value is
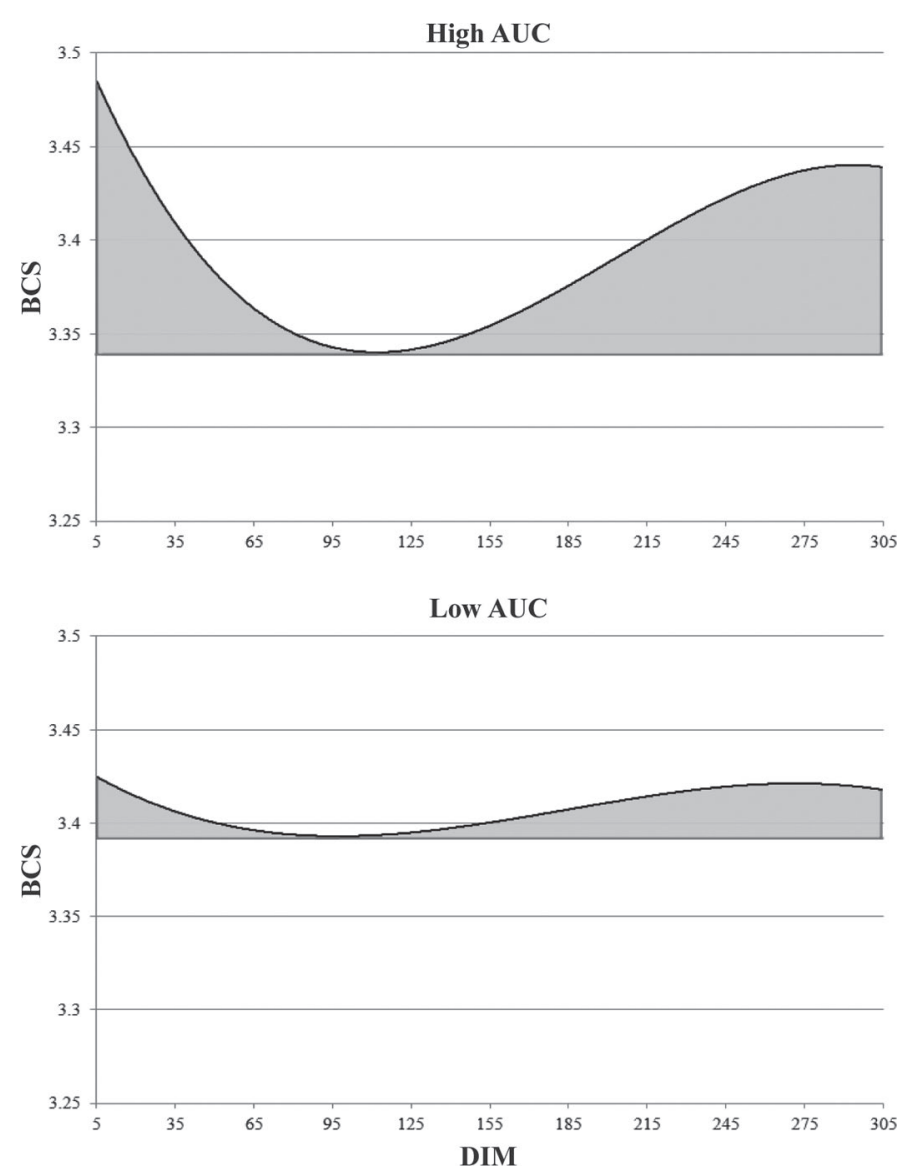

Figure 1. Illustration of area under the curve (AUC), a BCS EBV representing the area under the genetic BCS curve but no lower than the lowest point of the curve, where a lower AUC is more favorable, as it represents less change in the BCS curve. 
Table 1. Average daily genetic correlations (above the diagonal; diagonal indicated in bold), heritabilities (diagonal), and permanent environmental correlations (below the diagonal), with posterior standard deviations in parentheses, among the Valacta (Sainte-Anne-de-Bellevue, Québec, Canada) BCS and the Holstein Canada (Brantford, Ontario, Canada) BCS, angularity, and chest width ${ }^{1}$

\begin{tabular}{lcccr}
\hline Item & BCS1 & BCS2 & ANG & CW \\
\hline BCS1 & $\mathbf{0 . 2 6}(\mathbf{0 . 0 3})$ & $0.86(0.04)$ & $-0.69(0.06)$ & $0.56(0.07)$ \\
BCS2 & $0.65(0.08)$ & $\mathbf{0 . 2 3}(\mathbf{0 . 0 3})$ & $-0.75(0.06)$ & $0.72(0.06)$ \\
ANG & $-0.48(0.10)$ & $-0.44(0.23)$ & $\mathbf{0 . 1 6}(\mathbf{0 . 0 2})$ & $-0.28(0.09)$ \\
CW & $0.44(0.07)$ & $0.44(0.18)$ & $-0.07(0.27)$ & $\mathbf{0 . 1 6}(\mathbf{0 . 0 3})$ \\
\hline
\end{tabular}

${ }^{1} \mathrm{BCS} 1$ = Valacta's BCS; BCS2 = Holstein Canada's BCS; ANG = angularity; CW = chest width.

more favorable, as it represents an animal with less change in its genetic BCS curve, with a greater overall genetic BCS curve height. Equal weighting was placed on both AUC and INT.

(4) $1 / 3 A U C-2 / 3$ INT. This method of calculating an EBV is as described in (3), but with a weighting of $1 / 3$ on AUC and a weighting of $2 / 3$ on INT.

(5) $1 / 4 A U C-3 / 4 I N T$. This method of calculating an EBV is as described in (3), but with a weighting of $1 / 4$ on AUC and a weighting of $3 / 4$ on INT.

Sire BCS EBV calculated via the different models and methods described above were compared using the PROC CORR of SAS (SAS Institute Inc., Cary, NC). For all models and methods used to calculate BCS EBV, sires with $\geq 25$ daughters with BCS records were ranked, and the 10 best and 10 worst sires were compared. Specifically, average daughter BCS for every 30-DIM interval (5-30, 31-60, and so on to 271-305 DIM) were determined for the 10 best and 10 worst sires. These daughter averages were plotted and fitted with third-order polynomial trend lines for easy visual comparison. The purpose of this is for a simple comparison of the effect that selection on BCS EBV alone might have. Additionally, for comparison of some of the methods of calculating Valacta BCS EBV, average sire genetic BCS curves for the 10 best and 10 worst sires were calculated. Genetic BCS curves of sires with $\geq 25$ daughters were compared (as opposed to cow curves) because their genetic BCS curves are based on more information, and so should be more reliable. The average population phenotypic Valacta BCS curve was added to the sire genetic BCS curves and the resulting curve was plotted.

\section{RESULTS AND DISCUSSION}

\section{Variance Component Estimation for Valacta and Holstein Canada Traits}

$\boldsymbol{V A L}+\boldsymbol{H C}$ Model. Regarding Valacta's BCS, all results for daily heritability, and daily genetic, $\mathrm{PE}, \mathrm{HY}$, and residual variances were similar to those estimated by Loker et al. (2011). Table 1 displays the average daily heritability, and genetic and PE correlations between traits. Heritability estimates for BCS traits, $\mathrm{ANG}$, and $\mathrm{CW}$ were in the range of values found in the literature (Jones et al., 1999; Koenen et al., 2001; Berry et al., 2003b; Huapaya and Kistemaker, 2011; Loker et al., 2011, 2012a,b).

Strong genetic correlations existed between Holstein Canada's BCS, and ANG and CW (Table 1). Valacta's BCS was also strongly genetically correlated with ANG and $\mathrm{CW}$, although not as strongly, which is because the 2 BCS do not possess a genetic correlation of 1 (Table 1). Because both systems (Valacta and Holstein Canada) follow the Edmonson et al. (1989) method of scoring body condition, the lack of unity between the 2 BCS traits in this study might be due to the subjectivity of the recording procedure, differences in training, and differences in recording practices. Regardless, the 2 BCS traits were strongly genetically correlated. Figure 2 shows that the genetic correlations between Valacta's BCS and Holstein Canada's body traits were fairly constant throughout lactation. These correlations are consistent with other research linking cows with lower BCS to increased ANG and narrower chests (Berry et al., 2004), and this genetic inclination to be more frail has been linked with poor health and fertility (Royal et al., 2002; Berry et al., 2004).

$\boldsymbol{H C}_{\text {all }}$ Model. The estimated heritabilities $( \pm \mathrm{SD})$ of Holstein Canada's BCS, ANG, and CW were 0.21 (0.03), 0.22 (0.03), and $0.15(0.02)$, respectively. These values were similar to values found in the literature discussed above, although the heritability of ANG was higher than expected. The genetic correlations among traits were very similar to what was found for the $\mathrm{VAL}+\mathrm{HC}$ model. Body condition score was strongly genetically correlated with ANG and CW, with correlations of $-0.80(0.04)$ and $0.68(0.06)$, respectively. The genetic correlation between $\mathrm{ANG}$ and $\mathrm{CW}$ was -0.27 (0.10).

\section{$E B V$}

For each of the 5 methods of calculating Valacta BCS $\mathrm{EBV}$, daughter phenotypic BCS trend lines from 5 to 


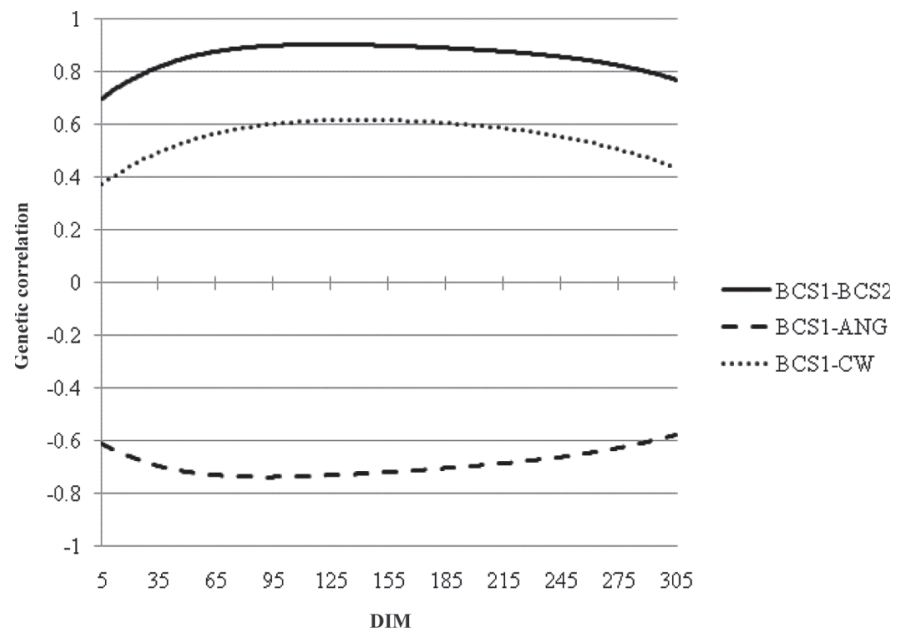

Figure 2. Estimates of genetic correlations between the Valacta (Sainte-Anne-de-Bellevue, Québec, Canada) BCS (BCS1) and the Holstein Canada (Brantford, Ontario, Canada) BCS (BCS2), angularity (ANG), and chest width (CW) across DIM.

305 DIM for the 10 best and 10 worst sires for BCS EBV are displayed in Figures 3 to 7 . Daughter phenotypic BCS trend lines for the 10 best and 10 worst sires for Holstein Canada BCS EBV calculated via the $\mathrm{HC}_{\text {all }}$ model are displayed in Figure 8. Daughters of sires with a lower AUC experienced an extended BCS loss in early lactation and did not replenish BCS reserves as quickly as daughters of sires with a greater AUC (Figure 3). Selection for reduced AUC (i.e., selection for minimum fluctuation in the genetic BCS lactation curve) may not improve the population's BCS lactation profile. Daughters of sires with a greater INT for Valacta's BCS did not lose as much body condition in early lactation compared with daughters of sires with a lower INT and ended the lactation with more tissue reserves (Figure 4). When AUC and INT were standardized and combined with equal weighting, daughters of the 10 best sires began and ended the lactation with similar BCS to daughters of the 10 worst sires, but lost less condition in early lactation (Figure 5). When AUC and INT were combined with a weighting of $1 / 3$ and $2 / 3$, respectively, the daughters of the 10 best sires started and ended the lactation with a higher BCS than the daughters of the 10 worst sires, and lost less condition in early lactation (Figure 6). When EBV were calculated by combining AUC and INT with a weighting of $1 / 4$ and 3/4, respectively, daughter BCS curves (Figure 7) showed a greater difference in height than was seen in Figure 6. When Holstein Canada BCS EBV were calculated using the $\mathrm{HC}_{\text {all }}$ model, daughters of the 10 best sires (sires with greater BCS EBV) started and ended the lactation with a higher BCS than daughters of the 10 worst sires, and lost less tissue reserves in early lactation (Figure 8).

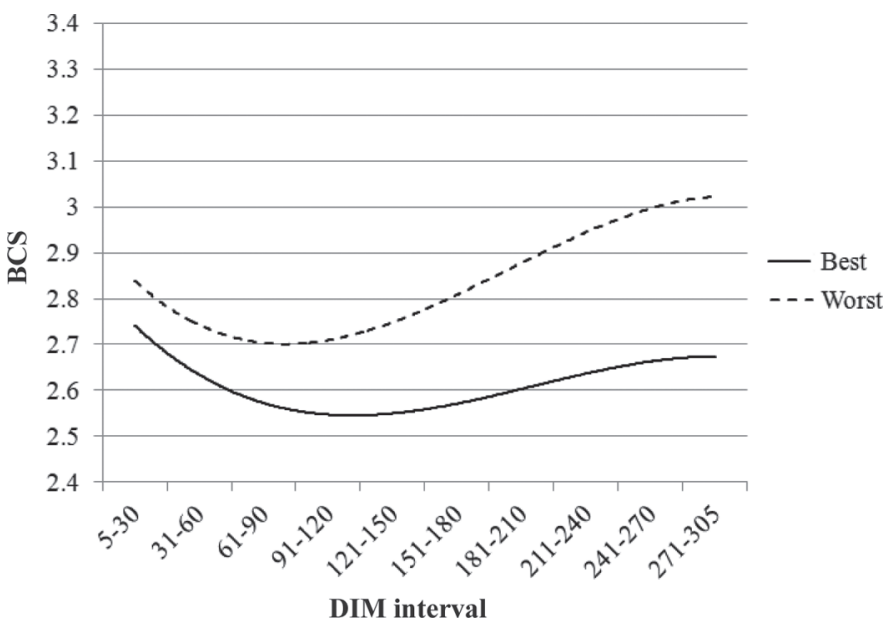

Figure 3. Average daughter phenotypic BCS curves for the 10 best and 10 worst sires for Valacta (Sainte-Anne-de-Bellevue, Québec, Canada) BCS EBV calculated using the AUC method (where AUC is the area under the BCS EBV curve, but no lower than the minimum BCS value of the curve, such that a lower AUC is more favorable, as it represents less change in the BCS curve).

Correlations of sire BCS EBV from each of the 5 methods used for calculating Valacta BCS EBV and from the $\mathrm{HC}_{\text {all }}$ model are displayed in Table 2. Sires with greater AUC (unfavorable) also tended to have greater INT (favorable). This correlation likely represents the similar increase in tissue replenishment seen in sire EBV curves for both sires with greater AUC (Figure 9) and sires with greater INT (Figure 10) relative to sires with lower AUC and INT. The genetic BCS curve of sires with lower AUC shows a greater loss of early lactation BCS with poor replenishment

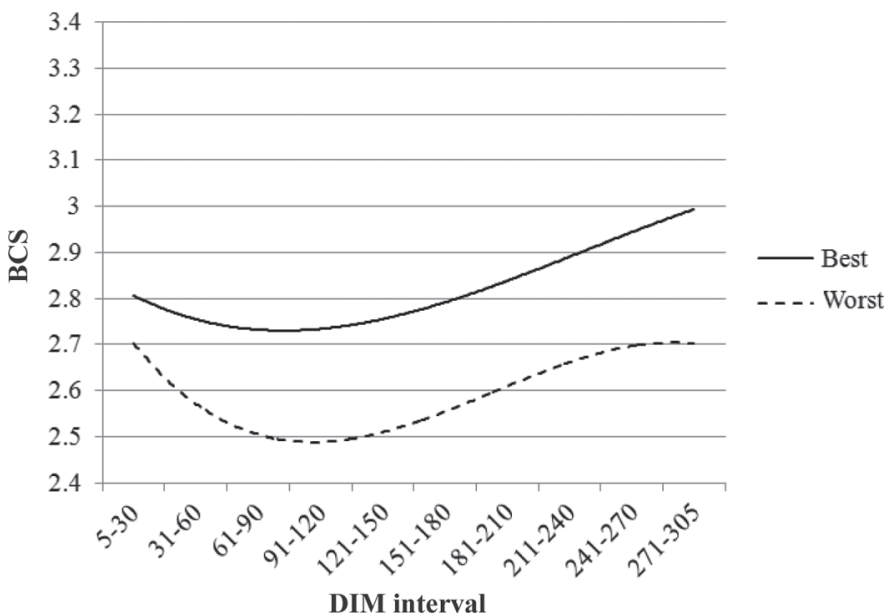

Figure 4. Average daughter phenotypic BCS curves for the 10 best and 10 worst sires for Valacta (Sainte-Anne-de-Bellevue, Québec, Canada) BCS EBV calculated using the INT method (where INT is the intercept EBV, representative of the height of the BCS EBV curve). 


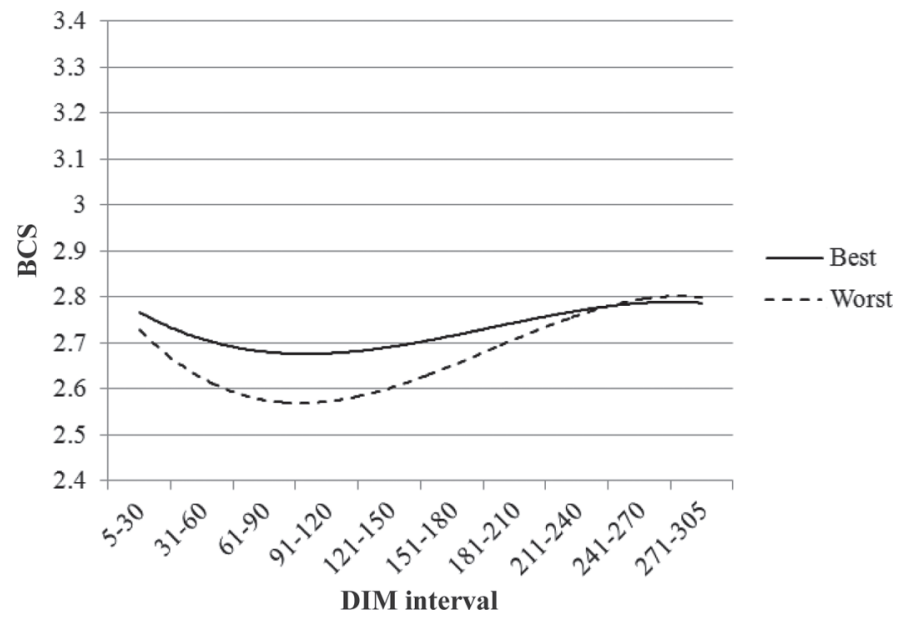

Figure 5. Average daughter phenotypic BCS curves for the 10 best and 10 worst sires for Valacta (Sainte-Anne-de-Bellevue, Québec, Canada) BCS EBV calculated using the AUC - INT method (where AUC - INT is the area under the BCS EBV curve, but no lower than the minimum $\mathrm{BCS}$ value on that curve, minus the intercept $\mathrm{EBV}$ ).

of tissue reserves (Figure 9). Differences in AUC from animal to animal appear to capture differences in tissue replenishment at the end of lactation, and seem to be less sensitive to initial BCS loss. This is probably because BCS tends to be more conserved in the population. Other studies have found initial BCS loss to be lowly heritable (0.01 to 0.09; Pryce et al., 2001; Dechow et al., 2002). Selection for reduced AUC should be avoided. The AUC - INT method resulted in sire EBV that were not strongly genetically correlated with other methods (Table 2). On average, the 10 best sires

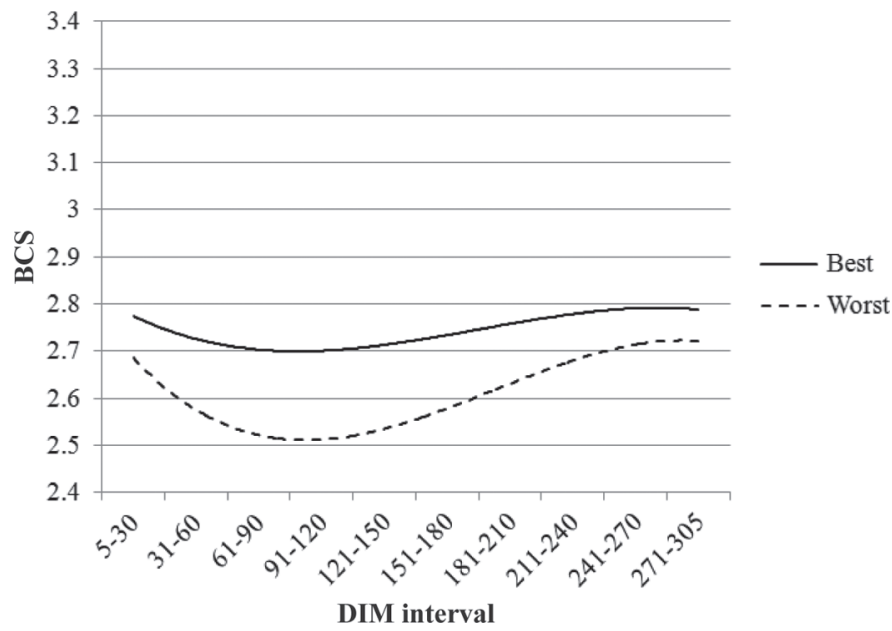

Figure 6. Average daughter phenotypic BCS curves for the 10 best and 10 worst sires for Valacta (Sainte-Anne-de-Bellevue, Québec, Canada) BCS EBV calculated using the $1 / 3$ AUC - 2/3 INT method (where $1 / 3$ AUC $-2 / 3$ INT is the area under the BCS EBV curve, but no lower than the minimum BCS value on that curve, minus the intercept EBV, with a weighting of $1 / 3$ and $2 / 3$, respectively).

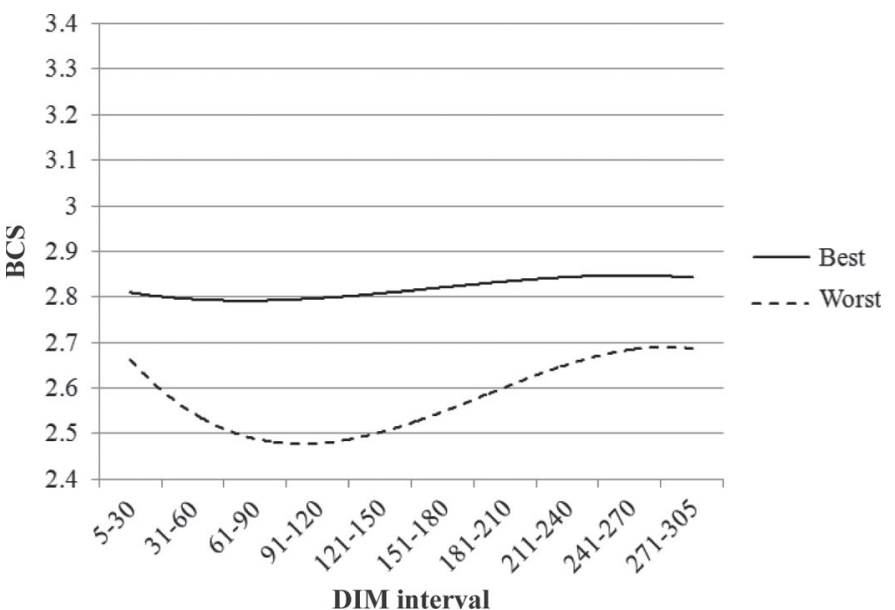

Figure 7. Average daughter phenotypic BCS curves for the 10 best and 10 worst sires for Valacta (Sainte-Anne-de-Bellevue, Québec, Canada) BCS EBV calculated using the $1 / 4$ AUC - 3/4 INT method (where 1/4 AUC - 3/4 INT is the area under the BCS EBV curve, but no lower than the minimum BCS value on that curve, minus the intercept EBV, with a weighting of $1 / 4$ and $3 / 4$, respectively).

for AUC - INT have a genetic BCS curve that begins and ends the lactation at a higher BCS than the 10 worst sires, but shows a similar loss of tissue reserves in early lactation, with less tissue replenishment by the end of lactation (Figure 11). Without considering AUC - INT, sire EBV were strongly correlated across the majority of the methods used for the calculation of BCS EBV (Table 2). Rather than using a more complicated method of calculating BCS EBV (for example using the $1 / 3$ AUC $-2 / 3$ INT or $1 / 4$ AUC $-3 / 4$ INT methods), INT or BCS EBV calculated via the $\mathrm{HC}_{\text {all }}$ model are very similar (with a genetic correlation of

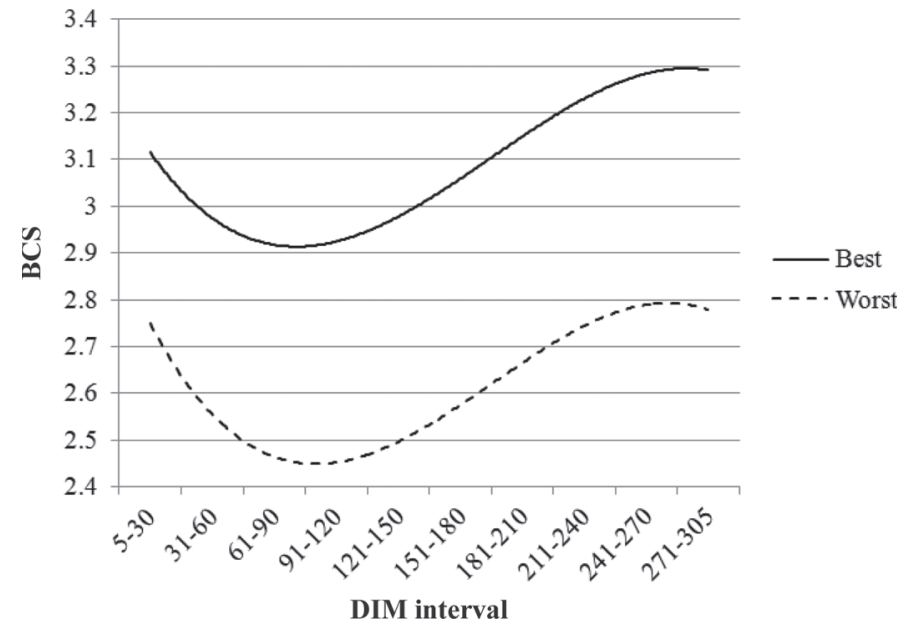

Figure 8. Average daughter phenotypic BCS curves for the 10 best and 10 worst sires for Holstein Canada BCS EBV calculated using the $\mathrm{HC}_{\text {all }}$ model [a multivariate model including the Holstein Canada (Brantford, Ontario, Canada) BCS, angularity, and chest width]. 
Table 2. Correlations of sire EBV for different methods and models used to calculate BCS EBV ${ }^{1}$

\begin{tabular}{|c|c|c|c|c|c|c|}
\hline Item & AUC & INT & AUC - INT & $1 / 4 \mathrm{AUC}-3 / 4 \mathrm{INT}$ & $1 / 3 \mathrm{AUC}-2 / 3 \mathrm{INT}$ & $\mathrm{HC}_{\text {all }}$ \\
\hline $\begin{array}{l}\text { AUC } \\
\text { INT } \\
\text { AUC }- \text { INT } \\
1 / 4 \text { AUC }-3 / 4 \text { INT } \\
1 / 3 \text { AUC }-2 / 3 \text { INT } \\
\mathrm{HC}_{\text {all }}\end{array}$ & & 0.87 & $\begin{array}{r}0.25 \\
-0.25\end{array}$ & $\begin{array}{r}-0.74 \\
-0.97 \\
0.47\end{array}$ & $\begin{array}{r}-0.60 \\
-0.92 \\
0.62 \\
0.98\end{array}$ & $\begin{array}{r}0.85 \\
0.96 \\
-0.23 \\
-0.94 \\
-0.88\end{array}$ \\
\hline \multicolumn{7}{|c|}{$\begin{array}{l}{ }^{1} \mathrm{AUC}=\text { area under the BCS EBV curve, but no lower than the lowest BCS value of the curve (a lower AUC i } \\
\text { more favorable); INT }=\text { the intercept EBV (representative of the height of the BCS EBV curve); AUC - INT } \\
=\text { standardized AUC minus standardized INT, with equal weighting; } 1 / 4 \mathrm{AUC}-3 / 4 \mathrm{INT}=\text { standardized } \\
\text { AUC minus standardized INT, with } 1 / 4 \text { and } 3 / 4 \text { weightings, respectively; } 1 / 3 \mathrm{AUC}-2 / 3 \mathrm{INT}=\text { standardize } \\
\text { AUC minus standardized INT, with } 1 / 3 \text { and } 2 / 3 \text { weightings, respectively; HC } \mathrm{C}_{\text {all }}=\text { Holstein Canada (Brantford } \\
\text { Ontario, Canada) BCS EBV, calculated from a multivariate model. }\end{array}$} \\
\hline
\end{tabular}

0.96) and simpler, and daughters of top-ranked sires for these methods show favorable phenotypic BCS curves compared with the other methods. To calculate INT, longitudinal Valacta BCS were analyzed using a random regression animal model for variance component estimation and estimating breeding values. Holstein Canada only needs to collect 1 BCS record per cow at classification and the resulting BCS EBV is strongly correlated with Valacta's INT. Additionally, a national genetic evaluation for Holstein Canada's BCS is easier to implement because it is recorded routinely across Canada. Additionally, the average daughter phenotypic BCS curve for the 10 best sires ranked using the $\mathrm{HC}_{\text {all }}$ model showed an increased overall BCS level compared with population phenotypic BCS level for first-parity Holsteins (Loker et al., 2011), which is currently too low. Meanwhile, the daughter curve of the 10 best sires ranked using the INT method showed no improvement

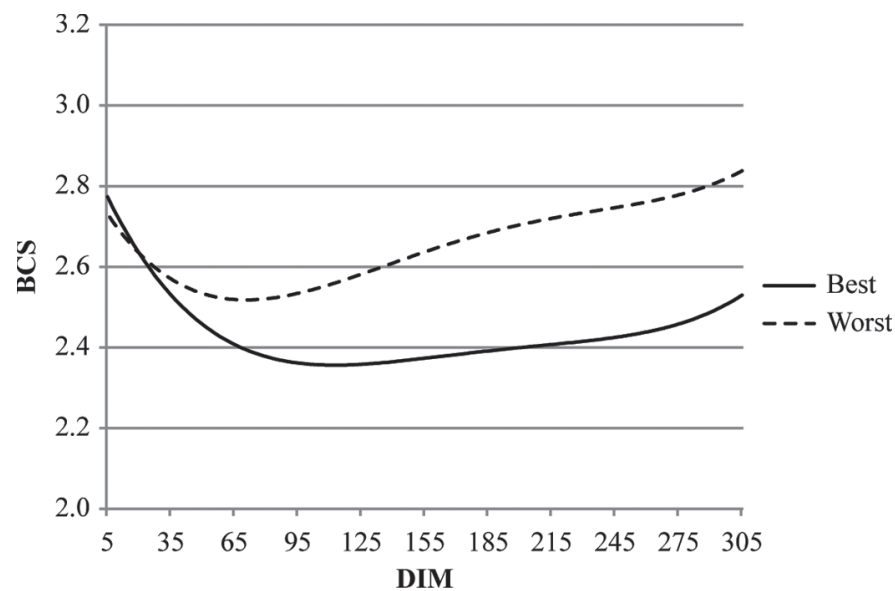

Figure 9. Average sire genetic BCS curve + average population phenotypic BCS curve for the 10 best and 10 worst sires for AUC (where AUC is the area under the BCS EBV curve, but no lower than the minimum BCS value of the curve such that a lower AUC is more favorable, as it represents less change in the BCS curve). in BCS level relative to the population phenotypic BCS level.

The results of this study do not eliminate the possibility of a genetic evaluation of BCS as a longitudinal trait, but instead indicate that other methods of calculating Valacta BCS EBV should be explored. Additionally, it would be beneficial if multiple BCS records were collected throughout the lactation on Canadian dairy cattle nationwide. Until that time, results of this study suggest that using a simple method of calculating BCS EBV may be effective in altering the level and shape of the population BCS curve.

As previously mentioned, the Canadian Holstein population has a lower BCS than is considered optimal. Hence, selecting for an overall increase in BCS is currently recommended. However, because BCS is an intermediate optimum trait, such that a BCS that is too low or too high is linked with increased risk of culling (Sewalem et al., 2011), the phenotypic level of the

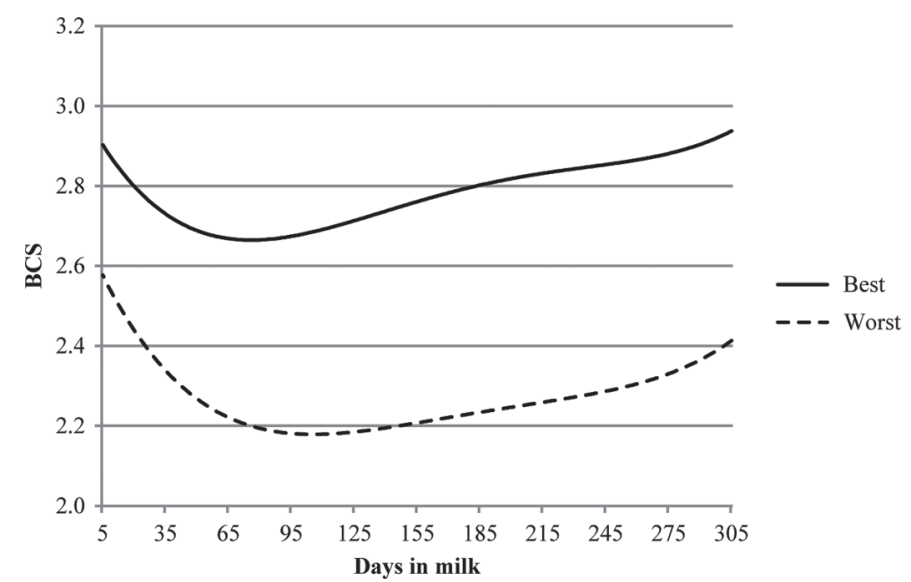

Figure 10. Average sire genetic BCS curve + average population phenotypic BCS curve for the 10 best and 10 worst sires for INT (where INT is the intercept EBV, representative of the height of the BCS EBV curve). 


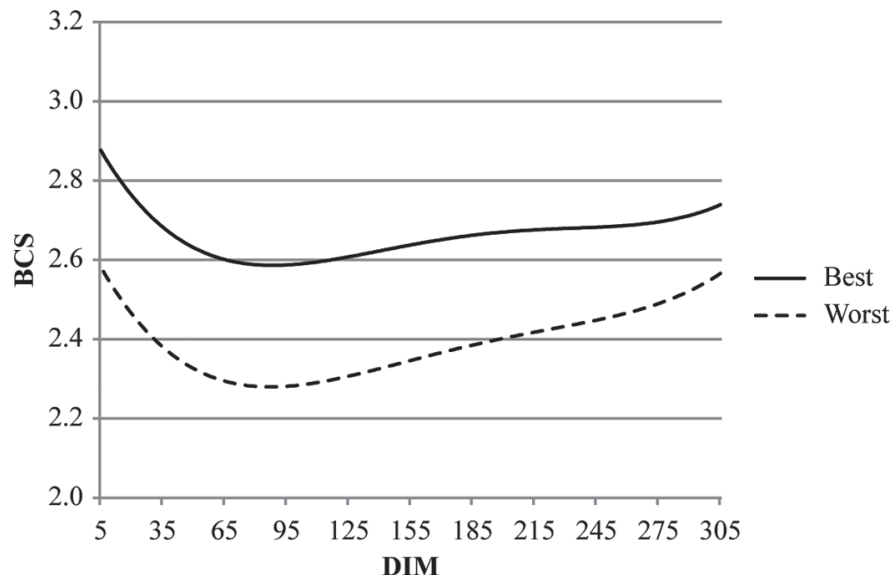

Figure 11. Average sire genetic BCS curve + average population phenotypic BCS curve for the 10 best and 10 worst sires for AUC INT (where AUC - INT is the area under the BCS EBV curve, but no less than the minimum BCS value on that curve, minus the intercept EBV).

Holstein population should be monitored because at some point, further change in BCS will not be desired.

\section{CONCLUSIONS}

Ranking sires based on the height of their Valacta genetic BCS curve was strongly correlated with more computationally complex methods of ranking BCS genetic curves, and was strongly correlated with ranking sires for their Holstein Canada BCS EBV. Daughters of sires ranked as best for their Valacta BCS EBV curve, or for their Holstein Canada BCS EBV possessed favorable phenotypic BCS curves relative to daughters of sires that ranked poorly, with a greater overall BCS level, reduced BCS loss in early lactation, and replenishment of reserves by the end of lactation. Currently, because Holstein Canada records BCS routinely and nationwide, a genetic evaluation for Holstein Canada's BCS is easier to implement, is genetically very similar to evaluating Canadian Holsteins for Valacta's longitudinal BCS, and may result in greater selection pressure on increasing overall BCS level.

\section{ACKNOWLEDGMENTS}

The authors acknowledge the DairyGen Council of Canadian Dairy Network (Guelph, ON, Canada) and Natural Sciences and Engineering Research Council (NSERC) of Canada (Ottawa, ON, Canada) for funding this project. The authors also thank N. Gengler of the University of Liège (Belgium) for his advice regarding the model used in this analysis. Additionally, appreciation is extended to Bill Szkotnicki, and Gordon Vander Voort of the University of Guelph (Ontario,
Canada), and Gerrit Kistemaker, Pete Sullivan, and Gladys Huapaya of Canadian Dairy Network for their assistance with this project.

\section{REFERENCES}

Banos, G., and M. P. Coffey. 2010. Genetic association between body energy measured throughout lactation and fertility in dairy cattle. Animal 4:189-199.

Bastin, C., S. Loker, N. Gengler, A. Sewalem, and F. Miglior. 2010a. Genetic relationships between body condition score and reproduction traits for Canadian Holstein and Ayrshire first-parity cows. J. Dairy Sci. 93:2215-2228.

Bastin, C., S. Loker, N. Gengler, A. Sewalem, and F. Miglior. $2010 \mathrm{~b}$. Genetic relationship between calving traits and body condition score before and after calving in Canadian Ayrshire second-parity cows. J. Dairy Sci. 93:4398-4403.

Berry, D. P., F. Buckley, P. Dillon, R. D. Evans, M. Rath, and R. F. Veerkamp. 2002. Genetic parameters for level and change of body condition score and body weight in dairy cows. J. Dairy Sci. 85:2030-2039.

Berry, D. P., F. Buckley, P. Dillon, R. D. Evans, M. Rath, and R. F. Veerkamp. 2003a. Genetic relationships among body condition score, body weight, milk yield, and fertility in dairy cows. J. Dairy Sci. 86:2193-2204.

Berry, D. P., F. Buckley, P. Dillon, R. D. Evans, M. Rath, and R. F. Veerkamp. 2003b. Genetic parameters for body condition score, body weight, milk yield, and fertility estimated using random regression models. J. Dairy Sci. 86:3704-3717.

Berry, D. P., F. Buckley, P. Dillon, R. D. Evans, and R. F. Veerkamp. 2004. Genetic relationships among linear type traits, milk yield, body weight, fertility and somatic cell count in primiparous dairy cows. Ir. J. Agric. Food Res. 43:161-176.

Dal Zotto, R., M. De Marchi, C. Dalvit, M. Cassandro, L. Gallo, P. Carnier, and G. Bittante. 2007. Heritabilities and genetic correlations of body condition score and calving interval with yield, somatic cell score, and linear type traits in Brown Swiss cattle. J. Dairy Sci. 90:5737-5743.

Dechow, C. D., G. W. Rogers, and J. S. Clay. 2002. Heritability and correlations among body condition score loss, body condition score, production and reproductive performance. J. Dairy Sci. 85:3062-3070.

Dechow, C. D., G. W. Rogers, U. Sander-Nielsen, L. Klei, T. J. Lawlor, J. S. Clay, A. E. Freeman, G. Abdel-Azim, A. Kuck, and S. Schnell. 2004. Correlations among body condition scores from various sources, dairy form, and cow health from the United States and Denmark. J. Dairy Sci. 87:3526-3533.

Edmonson, A. J., I. J. Lean, L. D. Weaver, T. Farver, and G. Webster. 1989. A body condition scoring chart for Holstein dairy cows. J. Dairy Sci. 72:68-78.

Hoekstra, J., A. W. van der Lugt, J. H. J. van der Werf, and W. Ouweltjes. 1994. Genetic and phenotypic parameters for milk production and fertility traits in upgraded dairy cattle. Livest. Prod. Sci. 40:225-232.

Huapaya, G., and G. Kistemaker. 2011. Heritability estimation for classification traits in the Holstein breed. March Dairy Cattle Breeding and Genetics Committee meeting. Accessed Feb. 5, 2013. http://cgil.uoguelph.ca/dcbgc/Agenda1103/Huapaya.pdf.

Interbull. 2011. Description of national genetic evaluation systems for dairy cattle traits as applied in different Interbull member countries. International Bull Evaluation Service, Uppsala, Sweden. Accessed Feb. 5, 2013. http://www-interbull.slu.se/national_ges_ info2/framesida-ges.htm

Jamrozik, J., J. Fatehi, G. J. Kistemaker, and L. R. Schaeffer. 2005. Estimates of genetic parameters for Canadian Holstein female reproduction traits. J. Dairy Sci. 88:2199-2208.

Jones, H. E., I. M. S. White, and S. Brotherstone. 1999. Genetic evaluation of Holstein Friesian sires for daughter condition-score changes using a random regression model. Anim. Sci. 68:467-475. 
Kadarmideen, H. N. 2004. Genetic correlations among body condition score, somatic cell score, milk production, fertility and conformation traits in dairy cows. Anim. Sci. 79:191-201.

Kadarmideen, H. N., and M. P. Coffey. 2001. Quality and validation of insemination data for national genetic evaluations for dairy cow fertility in the United Kingdom. Interbull Bull. 27:133-138.

Koeck, A., F. Miglior, D. F. Kelton, and F. S. Schenkel. 2012a. Alternative somatic cell count traits to improve mastitis resistance in Canadian Holsteins. J. Dairy Sci. 95:432-439.

Koeck, A., F. Miglior, D. F. Kelton, and F. S. Schenkel. 2012b. Genetic association of body condition score with disease resistance in first lactation Canadian Holsteins. Can. J. Anim. Sci. 92:285-289.

Koenen, E. P. C., R. F. Veerkamp, P. Dobbelaar, and G. De Jong 2001. Genetic analysis of body condition score of lactating Dutch Holstein and Red-and-White heifers. J. Dairy Sci. 84:1265-1270.

Loker, S., C. Bastin, F. Miglior, A. Sewalem, L. R. Schaeffer, J. Jamrozik, A. Ali, and V. Osborne. 2012a. Genetic and environmental relationships between body condition score and milk production traits in Canadian Holsteins. J. Dairy Sci. 95:410-419.

Loker, S., C. Bastin, F. Miglior, A. Sewalem, L. R. Schaeffer, J. Jamrozik, and V. Osborne. 2011. Short communication: Estimates of genetic parameters of body condition score in the first three lactations using a random regression animal model. J. Dairy Sci. 94:3693-3699.

Loker, S., F. Miglior, A. Koeck, T. F.-O. Neuenschwander, C. Bastin, J. Jamrozik, L. R. Schaeffer, and K. Kelton. 2012b. Relationship between body condition score and health traits in first-lactation Canadian Holsteins. J. Dairy Sci. 95:6770-6780.

Loker, S., F. Miglior, L. R. Schaeffer, J. Jamrozik, and V. Osborne 2010. Genetic parameters of body condition score, angularity, and chest-width in Canadian Holsteins. Presented to Dairy Cattle Breeding and Genetics Committee Meeting, Guelph, ON, October 2010. Accessed March 18, 2013. http://cgil.uoguelph.ca/dcbgc/ Agenda1010/Sarah-BCS+type.pdf.

Madsen, P., and J. Jensen. 2008. DMU: A User's Guide. A Package for Analysing Multivariate Mixed Models. Version 6, release 4.7. DJF, Foulum, Denmark. http://www.dmu.agrsci.dk/dmuv6_guideR4-6-7.pdf.

Miglior, F., B. L. Muir, and B. J. Van Doormaal. 2005. Selection indices in Holstein cattle of various countries. J. Dairy Sci. 88:12551263.
Negussie, E., I. Strandén, and E. A. Mäntysaari. 2008. Genetic association of clinical mastitis with test-day somatic cell score and milk yield during first lactation of Finnish Ayrshire cows. J. Dairy Sci. 91:1189-1197.

Neuenschwander, T. 2010. Studies on disease resistance based on producer-recorded data in Canadian Holsteins. PhD Thesis. University of Guelph, Guelph, ON, Canada.

Pryce, J. E., M. P. Coffey, and S. Brotherstone. 2000. The genetic relationship between calving interval, body condition score and linear type and management traits in registered Holsteins. J. Dairy Sci. $83: 2664-2671$

Pryce, J. E., M. P. Coffey, and G. Simm. 2001. The relationship between body condition score and reproductive performance. J. Dairy Sci. 84:1508-1515.

Roche, J. R., J. M. Lee, K. A. Macdonald, and D. P. Berry. 2007. Relationships among body condition score, body weight, and milk production variables in pasture-based dairy cows. J. Dairy Sci. 90:3802-3815.

Royal, M. D., J. E. Pryce, J. A. Woolliams, and A. P. F. Flint. 2002. The genetic relationship between commencement of luteal activity and calving interval, body condition score, production, and linear type traits in Holstein-Friesian dairy cattle. J. Dairy Sci. 85:3071-3080

Searle, S. R. 1982. Matrix Algebra Useful for Statistics. John Wiley \& Sons Inc., New York, NY.

Sewalem, A., G. Kistemaker, and F. Miglior. 2011. Relationship between body condition score, locomotion and dairy strength with functional longevity in Canadian Holsteins. September Dairy Cattle Breeding and Genetics Committee meeting. Accessed Feb. 5, 2013. http://cgil.uoguelph.ca/dcbgc/Agenda1109/Sewalem_ BCS_2011.pdf.

Shook, G. E. 1989. Selection for disease resistance. J. Dairy Sci. 72:1349-1362.

Veerkamp, R. F., and S. Brotherstone. 1997. Genetic correlations between linear type traits, food intake, live weight and condition score in Holstein Friesian dairy cattle. Anim. Sci. 64:385-392.

Wall, E., S. Brotherstone, J. A. Woolliams, G. Banos, and M. P. Coffey. 2003. Genetic evaluation of fertility using direct and correlated traits. J. Dairy Sci. 86:4093-4102.

Weigel, K. A. 2006. Prospects for improving reproductive performance through genetic selection. Anim. Reprod. Sci. 96:323-330. 